\title{
A participação do CBCISS no Movimento de Reconceituação e o Congresso da Virada
}

\section{CBCISS's participation in the Reconceptualization Movement and the Virada Congress}

\author{
Isaura G. C. Aquino ${ }^{a}$ \\ (D) https://orcid.org/0000-0002-3685-6199
}

\begin{abstract}
Resumo: O objetivo é debater o CBCISS, como partícipe do Movimento de Reconceituação, considerando o Serviço Social na história e evidenciando suas contradições e antagonismos. O CBCISS, expressão da modernização e do conservadorismo no Brasil, apontou a reflexão para as mediações existentes na realidade brasileira no declínio da ditadura civil-militar e a rearticulação dos trabalhadores, incluindo os assistentes sociais, que redunda no Congresso da Virada e na perda de hegemonia do CBCISS.
\end{abstract}

Palavras-chave: Serviço Social. CBCISS. Movimento de Reconceituação. Congresso da Virada.

\begin{abstract}
The objective is to discuss the CBCISS, as a participant in the Reconceptualization Movement, considering Social Work in history and highlighting its contradictions and antagonisms. CBCISS, an expression of modernization and conservatism in Brazil, pointed to the reflection on existing Brazilian mediations in the decline of the civil-military dictatorship and the rearticulation of workers, including social workers, which is happening in the Virada Congress and in the loss of hegemony of CBCISS.
\end{abstract}

Keywords: Social Work. CBCISS. Reconceptualization Movement. Congress of the Virada. 


\section{O golpe de 1964: dos anos de chumbo à decadência da ditadura}

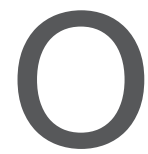

golpe civil-militar no Brasil, financiado e intencionalmente direcionado pelos EUA, logo ceifa, pela cabeça, a potencialidade dos questionamentos que emergem a partir do Encontro de Porto Alegre, em maio de 1965.

Em 1964, a hegemonia econômica e bélica do Estado norte-americano promove uma contrarrevolução preventiva com a finalidade de adequar os padrões de desenvolvimento nacionais ao novo quadro do inter-relacionamento econômico capitalista por meio da intensificação da internacionalização do capital, bem como de imobilizar os protagonistas sociopolíticos habilitados a resistir a essa reinserção mais subalterna no sistema capitalista. Visava ainda dinamizar todas as tendências que podiam ser catalisadas contra a revolução e o socialismo. Em face disso, a articulação político-social do Estado brasileiro pós-1964 teve como meta garantir os interesses do grande capital, principalmente a favor dos monopólios imperialistas com vistas a "assegurar a reprodução do desenvolvimento dependente e associado" (Netto, 1994, p. 27), aprofundando a exclusão historicamente constituída, ou seja, proceder no âmbito econômico como repassador de renda para os monopólios e, no âmbito político, como mediador de conflitos entre o capital nativo e as grandes corporações transnacionais.

O período entre 1968 e 1974 é decisivo para a implantação do modelo econômico racionalizado, caracterizado como "modernização conservadora”. A concentração e a centralização de capital no país foram viabilizadas, principalmente, pelo Paeg (Programa de Ação Econômica do Governo), que excluiu de sua pauta qualquer medida favorável aos segmentos populares da sociedade brasileira, controlados pelo AI-5. Desse modo, o Paeg visou combater a inflação, ampliar os investimentos estatais, reformar o Sistema Financeiro Nacional, diminuir as desigualdades regionais entre o Norte e o Sul, sob a ótica do grande capital e das empresas coorporativas multinacionais, e viabilizar e ampliar os investimentos externos. 
O governo autocrático burguês compreendia a inflação como resultado do excessivo consumo. Assim, o Paeg previu a diminuição do consumo restringindo o crédito. Abre-se a fenda necessária à funcionalidade econômica do Estado (burguês) estruturado e organizado para a vigência do projeto modernizador, com o "milagre econômico". O terrorismo de Estado ou, de acordo com Alves (1987), a cultura do terror, é a outra face do Estado, que lhe dá autoridade para a implantação do modelo econômico de modernização conservadora.

O AI-5, em 1968, demarca a ditadura civil-militar em seu ápice e, com a crise do milagre econômico, em 1974, tem início também uma crise no âmago da autocracia burguesa. Tanto Geisel quanto Figueiredo buscaram dirimir a crise com um projeto que visava reformar, por dentro, os princípios autocrático-burgueses. Os anos compreendidos entre 1974 a 1979 dão significado ao projeto de autorreforma do Estado autocrático burguês. No último trimestre de 1978, é divulgado um "pacote de reformas", como a extinção do AI-5 e de todos os atos vinculados e leis complementares. Apesar de não extirpar a lógica fascista e perversa da autocracia burguesa, foi um indicador de conquista e fortalecimento dos alentos democráticos. Logo depois, o governo fez alterações na Lei de Segurança Nacional, como a retirada da pena de morte e da prisão perpétua. Concomitante, a reação dos segmentos operários em seu processo organizativo, principalmente dos trabalhadores sindicalizados do ABC paulista e o fim do milagre econômico, associado às elevadas taxas de juros da dívida externa, levam o país a reconhecer o desastre do modelo econômico e a declarar moratória parcial, uma vez que os juros da dívida (externa) continuaram sendo pagos, levando o processo reprodutivo da ditadura civil-militar à bancarrota (Netto, 2014).

\section{O Movimento de Reconceituação do Serviço Social brasileiro: a história e suas contradições}

O Serviço Social brasileiro, cunhado sob a influência do Serviço Social europeu e norte-americano, redundou da confluência de heranças 
ideológico-culturais e científicas sincréticas, alinhado ao caráter antidemocrático, tendencialmente à direita, fundamentalmente reformista, de cariz restaurador e reacionário (Netto, 1992), inserido na divisão social e técnica do trabalho (Iamamoto e Carvalho,1988), em conformidade com o desenvolvimento do capitalismo periférico e dependente latino-americano (Fernandes, 1975), de nações "livres" politicamente, mas “dependentes" economicamente (Fernandes, 1981)1. Desse veio liberal-burguês, o Serviço Social tradicional - compreendido enquanto prática empirista, pragmática, burocratizada, mediata, sustentada no positivismo e sua tradição e na orientação psicossocial; frágil teórico-metodologicamente na explicação da particularidade latino-americana; incapaz ético e politicamente de compreender a questão social e intervir a partir dela - entra em crise nos anos 1960. Os determinantes sociais, culturais e políticos, que fizerem emergir a crise, já foram suficientemente analisados (Netto, 1994). Entretanto, cabe dar relevo à conjuntura nacional e internacional, marcada por mudanças de comportamentos, como os acontecimentos de maio de 1968 na França; o início da crise do Estado de bem-estar social, evidenciando suas deficiências e incongruências na sustentabilidade do modelo de produção fordista/keynesiano (Antunes, 2000 e 2006; Antunes e Druck, 2014, Bihr, 2014; Alves, 2006 e 2000; Braga, 1997) e, enquanto legislador e defensor dos interesses do capital monopolista, com ressalvas para a particularidade latino-americana (Braverman, 1987; Baran e Sweezy, 1974; Netto, 1992; Harvey, 2006), de manter a política de pleno emprego e os altos salários característicos do fordismo; a tomada de posição anticapitalista das Igrejas (católica e algumas protestantes); a contestação e crítica do movimento estudantil; e, finalmente, e não menos importante, a autocrítica das Ciências Sociais (Netto, 1994), que rebateram diretamente no Serviço Social na compreensão da função social e legitimidade profissionais, responsáveis pela ocupação dos espaços

\footnotetext{
Não obstante, essa condição de dependência externa não elimina o caráter contraditório da história que, segundo Fernandes (2008, p. 31), "apresenta uma enorme variedade de situações histórico-sociais distintas" em face dos países europeus e dos Estados Unidos, e põem à mostra as possibilidades sócio-históricas e socioculturais das nações subdesenvolvidas.
} 
sócio-ocupacionais historicamente constituídos. Tem início o Movimento de Reconceituação que, com toda heterogeneidade, representa a crítica ao Serviço Social tradicional e à subalternidade teórico-prática da profissão.

A gênese do Movimento de Reconceituação foi demarcada pelo questionamento de como o Serviço Social poderia contribuir para a proposta desenvolvimentista (Netto, 2005a e 2005b). As primeiras propostas construíram uma frente contra o Serviço Social tradicional, compondo um coletivo profissional heterogêneo, dividido em dois grupos: os interessados em modernizar o Serviço Social de modo a atender as demandas do mercado (modernização conservadora) compatíveis com o projeto desenvolvimentista; e os radicais com vistas à ruptura com o passado profissional e da supressão da exploração (Netto, 2005a).

Como parte do segundo grupo, Aquín (2005) afirma que a Reconceituação pode ser considerada uma desconformidade política com o saber acadêmico instalado, em uma crítica negativa, tanto para o exercício profissional, como para os arranjos institucionais em que o exercício profissional tem lugar. Desconformidade crítica que emerge no calor da irrupção de novos discursos, de novos governos e novos movimentos sociais e políticos. Esses são a expressão e o resultado de um tempo de profunda e extensa radicalização política, que convida todas as disciplinas sociais à remoção de suas perspectivas ideológicas, seus fundamentos teóricos e caminhos metodológicos até aquele momento transitado. Expressa uma ruptura e, como tal, se compreende a partir de um tempo e espaço que confluem condicionantes que têm contribuído para a formação de seus conceitos, seus objetos, opiniões e procedimentos.

La Reconceptualización asume a pleno a lucha por otorgar um sentido y uma direccionalidad al Trabajo Social, y ló hace a través de um discurso apologético, caliente, cargado de adjeticaviones, acorde com el clima de agitación general em que se desarrolla. (Aquín, 2005, p. 41)

Alayón (2005), como integrante de um grupo que pretendia a ruptura com o passado profissional, aponta que, como em todo campo de 
estudos, a ação do trabalho social sempre tem uma objetiva dimensão política. Sendo assim, o assistente social opera em duas frentes oscilantes: legitimar ou questionar a ordem social vigente em um período determinado, haja vista a diversidade de acepções ideológicas e políticas dos profissionais que propunham a Reconceituação composta por católicos, evangélicos, peronistas, comunistas, socialistas e democratas-cristãos. $O$ sentimento comum antiamericano e em tudo que era proveniente dos EUA era o eixo comum entre todos. A turbulência e a convulsão que haviam ocasionado as novas ideias e os profissionais mais tradicionais davam passos largos às denúncias e estigmatizações para setores que aderiam às novas correntes da Reconceituação.

Em rigor, el movimiento de Reconceptualización se había iniciado con un sesgo de adhesión al modelo desarrollista, para luego ir transitando hacia posiciones más radicalizadas, en la perspectiva de posicionar el quehacer del Trabajo Social en el marco de la opresión y explotación que sufría América Latina y de las emergentes y/o inminentes experiencias "revolucionarias". (Alayón, 2005, p. 41)

Netto (2005b) ressalta quatro conquistas da Reconceituação para o Serviço Social latino-americano, que desde então integraram-se à dinâmica profissional: a articulação de uma nova concepção da unidade latino-americana, a fim de que fosse criada uma interação entre profissionais para se tornar possível responder às problemáticas comuns desses países; a explicitação da dimensão política da ação profissional, uma vez que o tradicionalismo teve em sua raiz a dimensão política que é característica de qualquer intervenção social; a interlocução crítica do Serviço Social com as Ciências Sociais, rompendo com a perspectiva acrítica dos produtos das Ciências Sociais acadêmicas; e, por último, a inauguração do pluralismo profissional, tendo a Reconceituação aberto um leque de possibilidades a diferentes concepções acerca da natureza, do objeto, das funções, dos objetivos e das práticas do Serviço Social. 
Iamamoto (1998) comunga da análise de que o Movimento de Reconceituação do Serviço Social latino-americano, incluindo de fato o Brasil, foi "um marco decisivo no desencadeamento do processo de revisão crítica do Serviço Social no continente" (p. 205; grifos da autora). É também, desde o seu início, "um movimento de denúncia - de autocrítica e de questionamentos societários - que tinha como contraface um processo seletivo de busca da construção de um Serviço Social latino-americano" (Iamamoto, 1998, p. 207; grifos da autora).

Não obstante, a Iamamoto concorda, como outros autores citados até aqui, que o Movimento de Reconceituação não foi um movimento homogêneo e único, ainda que o principal confronto tenha sido com o Serviço Social tradicional.

Ao contrário: tanto em função de suas gêneses sociais diferenciadas - determinadas por contextos sociopolíticos e econômicos distintos - , quanto em razão da vinculação intelectual e política por parte de seus protagonistas a matrizes teóricas e societárias também diversas, o movimento de reconceituação se molda como uma unidade repleta de diversidades. Essas se manifestam não só na forma de construção das críticas e propostas, mas também no conteúdo atribuído ao "novo" no Serviço Social latino-americano. (Iamamoto, 1998, p. 207)

Todavia, diante de compreensões diferenciadas e até mesmo divergentes do Serviço Social na história e das perspectivas teórico-metodológicas que despontam das questões convergentes e contraditórias, Junqueira (1980), então professora da PUC/SP e membro do CBCISS (Centro Brasileiro de Cooperação e Intercâmbio de Serviços Sociais), apresenta que o Movimento de Reconceituação foi conduzido pelas tentativas de práticas desenvolvimentistas e pelo impacto das novas teorias que estavam nos campos das Ciências Sociais. Para a autora, é no Brasil, em janeiro de 1964, quando ocorreu o Encontro Regional de Escolas de Serviço Social do Nordeste, que houve a primeira manifestação crítica ao Serviço Social tradicional. Portanto, naquele espaço estava o início 
do Movimento de Reconceituação. No Brasil, ainda conforme Junqueira (1980), o Encontro de Araxá (1967), promovido pelo CBCISS, tem o propósito de pensar a teoria dos assistentes sociais, bem como sua metodologia. A autora também afirma que

A crítica, no segundo lustro de sessenta, à validade dessa metodologia para o Serviço Social latino-americano foi o fator desencadeante do movimento de reconceituação, em razão de uma tomada de consciência da inadequação do preparo profissional para atender as condições de subdesenvolvimento deste continente. (Junqueira, 1980, p. 14)

Para a autora, nem as sociedades socialistas da época conseguiram acabar com o trabalho dos assistentes sociais, haja vista a incapacidade de qualquer sociedade de sobreviver em condições de igualdade social. Além disso, o Movimento de Reconceituação não deslocou toda a categoria profissional para a mesma teoria básica e entende que "as diferentes correntes ou tendências não significam áreas estanques de pensamento, mas uma diversidade em enfoques e respostas" (Junqueira, 1980, p. 13).

Para Junqueira (1980), o Movimento de Reconceituação tinha um posicionamento ideológico frente à realidade latino-americana, bem como um esforço de construir uma prática e uma teoria distinta da profissão que estava posta. A autora também reconhece que o movimento foi uma busca de converter o exercício profissional dos assistentes sociais em uma práxis científica, além de demonstrar uma ação profissional única para o Serviço Social. Porém conceitua que o método dialético-materialista não faz menção em como deveria ser a atuação dos profissionais, apesar de ser um excelente instrumento de análise da realidade. Ressalta-se que em julho de 1979, em Caracas, acontece o IX Seminário Latino-Americano de Trabajo Social (Celats/Alaets) em que autores e pesquisadores discutem o distanciamento da teoria com a prática.

Junqueira (1980), ao longo de seu texto, constrói três argumentos indagando a efetividade do Movimento de Reconceituação. 
Muito difícil comentar uma experiência dessa natureza sem conhecer todo o contexto. Contudo, o grau de comprometimento da prática dos alunos com a ação política parece ter sido viável em um contexto universitário, assumido plenamente pela instituição, em determinado contexto político. Indaga-se em que outros contextos institucionais ou de movimentos não institucionalizados seria viável essa prática, no exercício da atividade por profissionais? (Junqueira, 1980, p. 28)

Cabe lembrar, no entanto, pronunciamentos de alguns representantes da "reconceituação", no sentido de que seja revista a postura radical generalizada, que levava muitos a admitirem a impossibilidade de ser exercido o Serviço Social de linha "reconceituada" em instituições. Significa admitir-se que sua operacionalização somente seria viável em atividade direta assistente social/população (difícil de conceber-se enquanto exercício profissional remunerado) ou em instituições de caráter muito especial, ou ainda, apenas, como campo-piloto de Universidades, o que poderia ter um papel demonstrativo de alta valia, mas que dificilmente poderia generalizar-se em programas para a grande maioria objeto — sujeito dessa ação. (Junqueira, 1980, p. 31)

Conjectura-se, entretanto, face a conflitos dessa natureza, se seria ou não possível desenvolver estratégias e táticas que permitam abrir alguns caminhos, embora com alguma concessão, não quanto a questões essenciais, ou se seria o caso de concluir-se que o exercício operativo do Serviço Social "reconceituado" é inviável no sistema vigente, além de algumas tentativas de efeito demonstrativo. (Junqueira, 1980, p. 32)

Contudo, Netto (1989) afirma que a tradição marxista contribuiu para uma qualificação da profissão com sua teoria crítica, o que fez com que a profissão se afastasse das Ciências Sociais, que, de certo modo, não respondiam à demanda da compreensão da questão social e dos impasses teórico-práticos que os profissionais vivenciavam. Deste modo, o marxismo contribuiu para a construção da identidade da profissão, bem como para a intervenção socioprofissional. O autor complementa que a categoria profissional encontrou na tradição marxista respostas efetivas 
para o Serviço Social, como as condições de trabalho, a compreensão cultural da sociedade burguesa e a compreensão do processo da revolução.

1. Sem Marx, e a tradição marxista, o Serviço Social tende a empobrecer-se — independentemente da sua filiação teórica e ideopolítica, o assistente social necessita travar um diálogo sério com Marx e a tradição marxista, sob pena de perder determinações essenciais da sua prática, de fragilizar a sua reflexão teórica e de isolar-se dos debates culturais e profissionais contemporâneos;

2. Sem considerar as práticas dos assistentes sociais, a tradição marxista pode deixar escapar elementos significativos da vida social - as práticas dos assistentes sociais frequentemente incidem sobre processos que, tratados pelo referencial teórico-metodológico de Marx, oferecem insumos para a sua verificação e enriquecimento;

3. Por mais que seja rigorosa, intensa e extensa a interlocução com a tradição marxista, não se constituirá um Serviço Social "marxista" — enquanto profissão, o Serviço Social sempre contemplará uma tal inclusividade que no seu campo se moverão legitimamente profissionais que, incorporando diferentes expressões do pensamento contemporâneo, encontrarão espaços de prática e intervenção diversos e plurais. (Netto, 1989, p.101)

Em contraponto, Almeida (1974, p. 30-31), professora da PUC/RJ e membro do CBCISS, com um posicionamento singular, mas que indubitavelmente representa um grupo significativo de assistentes sociais, retrata a profissão com base em três postulados valorativos: "igualdade ontológica de todos os homens", "sociabilidade essencial da pessoa" e "perfectibilidade humana". Desse modo, o Serviço Social se constituía de movimentos exteriores e interiores, os quais estavam associados à perspectiva dialética.

Almeida associa a profissão a processos psicossociais, que devem ser trabalhados pelo assistente social conforme a experiência e o desejo de seu "cliente"; o assistente social deve sempre colaborar para a construção de alternativas para o cliente. 
Ao concretizar o humano na dimensão social das realidades cotidianas, em diversos momentos do desenvolvimento do projeto são colocadas em foco relações dialéticas, principalmente em situações onde há dificuldade de conciliar exigências pessoais e dos outros, conflitos de papéis. Quando o cliente vê como é difícil realizar o projeto, quando fracassam algumas tarefas, quando se angustia na busca do aperfeiçoamento, é chegado o momento de autorreconhecer. (Almeida, 1974, p. 32)

Assim, a autora considera que há processos em que o cliente deve ultrapassar com a ajuda do assistente social, sempre associando os seus conflitos com mecanismos psicossociais. Porém já aponta que não há como discorrer sobre "caso social" sem analisar onde o cliente está inserido ou onde o caso está sendo gerado. "Nosso conceito de participação é fundado, inteiramente, no sentido que lhe foi dado por Mary Richmond" (Almeida, 1974, p. 32). O que se apresenta ao longo do texto são esquemas interpretativos sobre o processo cliente/profissional e que o movimento de amadurecer a relação teoria-prática não é suficiente para o desenvolver da profissão.

Tal proposição não basta para atingirmos um novo estágio, se não tivermos possibilidades de trabalhar com as pressões criadas por critérios de verificação, desprovidos de ambiguidades. Mais ainda. Se as premissas colocadas pela teoria do Serviço Social são verdadeiras, se a exigência de reconceituação reflete, sobretudo, uma realidade objetiva — o estágio da disciplina - , a solução teórica é sem dúvida insuficiente. (Almeida, 1974, p. 34)

Assim, como exposto, o Movimento de Reconceituação latino-americano de base ideológica dos profissionais não é suficiente para caracterizar e auxiliar a profissão. Considera-se que o modelo psicossocial é mais amplo e mais assertivo diante da sociedade. Para a autora, o momento de reconceituação da profissão ainda estava por vir e tinha vinculação com os padrões de desempenho dos profissionais ativos. 


\section{O CBCISS no contexto da derrocada da ditadura civil-militar e o Congresso da Virada}

Interessa aqui recortar o lapso temporal compreendido no período entre 1974 e 1979, interstício que compreende a crise do golpe civil-militar em face da sua incapacidade de reproduzir-se, haja vista o caráter diacrônico da sistematização profissional nesse período, que culmina na "virada" profissional a partir do III Congresso Brasileiro de Assistentes Sociais.

A heterogeneidade do Movimento de Reconceituação, debatida na seção anterior evidencia de que forma e por quais direções teórico-metodológicas perpassou, com a predominante influência do CBCISS nos marcos da ditadura civil-militar, haja vista que o Serviço Social foi marcado pela hegemonia da vertente modernizadora, funcional ao Estado autocrático burguês e ao "novo" mercado de trabalho que se abria, àquela época, para os assistentes sociais (Netto, 1994).

Em face da hegemonia da vertente modernização conservadora no período entre 1964 e 1978, a articulação da categoria profissional em torno dos debates acerca da teoria (da sua influência na profissão ou, ainda e principalmente, na busca de uma teoria própria do Serviço Social), método, prática e formação profissional "é praticamente monopolizado pelo CBCISS, que então abre a série dos seus importantes 'seminários de teorização'" (Netto, 1994, p. 152 e 153), que capta profissionais e docentes para o seu interior e se coloca como representante da categoria profissional. Essa incorporação generalizada da categoria delega ao CBCISS (Centro Brasileiro de Cooperação Internacional em Serviços Sociais) o debate e a ação, praticamente exclusivos no interior dos cursos de graduação e pós-graduação. Impõe orientação, tanto no âmbito da formação profissional, no interior das Escolas de Serviço Social, quanto na organização da categoria e no mercado de trabalho. Amplia o universo de interlocutores em razão da pluralidade de sujeitos, organismos envolvidos e do aumento do número de profissionais, aos quais, em face da repressão política e cultural do Estado autocrático burguês e de seus 
representantes policialescos e torturadores, não restavam muitas opções de espaços coletivos.

Essa centralidade do CBCISS tem, também, relação direta com a difusão dos conteúdos pesquisados, elaborados e difundidos durante a Reconceituação do Serviço Social. Assistentes sociais de maior expressão intelectual e profissional se concentram no CBCISS, com capacidade inaudita para disseminar os eixos fundamentais do processo do Movimento de Reconceituação no Brasil e em suas expressões e participações internacionais (CBCISS, 2002). Duas, das três direções que o processo de renovação do Serviço Social no Brasil suscitou, tem o CBCISS como expressão central do movimento.

A direção denominada por Netto (1994) de modernização conservadora engendrou um mercado nacional de trabalho macroscópico e consolidado para os assistentes sociais. Com o desenvolvimento das forças produtivas houve uma saturação do Serviço Social brasileiro com todas as refrações da questão social, hipertrofiadas e com sua administração centralizada pelas políticas sociais do Estado ditatorial. A partir de então, os assistentes sociais não só trabalhavam nos aparelhos burocráticos do Estado, como também nos setores geridos pelo capital. Quando o Estado se organiza e se racionaliza para gerenciar o processo em prol dos monopólios, muda o sentido não só das políticas setoriais, mas também da malha organizacional que as executa e planeja. Ocorre uma reformulação nos tradicionais empregadores de assistentes sociais em 1966-67 nos níveis organizacional e funcional.

Na década de 1960, o mercado de trabalho dos assistentes sociais era irregular e reduzido. A partir do crescimento industrial advindo do milagre econômico, esse mercado de trabalho se torna expressivo. Surge o que se convencionou chamar de "Serviço Social de empresa". A "modernização conservadora" exigiu um novo padrão de desempenho profissional, associado à racionalidade burocrático-administrativa da "modernização", que passou a requisitar do assistente social uma postura moderna no sentido de compatibilizar seu desempenho com normas, 
fluxos e rotinas. A prática teve que se revestir com características formais e processuais, possibilitando o seu controle e verificação, segundo critérios burocrático-administrativos das instâncias hierárquicas e sua interseção com outros profissionais.

A modernização conservadora revela-se nesse domínio, na base da legitimidade profissional, nas exigências do mercado de trabalho e do quadro de formação que redefinem o Serviço Social.

O Movimento de Reconceituação no Brasil pode ser entendido como um conjunto de características novas que o Serviço Social articulou, rearranjando suas tradições e sua assunção do contributo de tendências do pensamento social contemporâneo, procurando investir-se da instituição de natureza profissional, dotada de legitimidade prática, com respostas às demandas sociais, à sua sistematização e validação teórica, mediante a remissão às teorias e disciplinas sociais (Netto, 1994). Foi também um processo global que envolveu toda a profissão em decorrência da laicização, implicando a construção de um pluralismo profissional, porém sem atenuar as contradições do cariz comum às suas vertentes. $O$ esforço de validação teórica (Netto, 1994) procurou dar fundamento sistemático a todos os componentes do processo profissional (análises, diagnoses etc.) e recorreu a um elenco de fontes teóricas, ideológicas e culturais para operar aquela fundamentação. Para além do esforço de validação teórica, cabe destaque, no Movimento de Reconceituação do Serviço Social brasileiro, a instauração do pluralismo teórico, ideológico e político questionando a exclusividade da tradição positivista. Tal questionamento foi possível em face do momento conjuntural. O processo de declínio da ditadura civil-militar abre fendas significadas a outras duas vertentes que, no Seminário de Sumaré, realizado pelo CBCISS, no período entre 20 e 24 de novembro de 1978, se encontra numa situação de abertura, com certeza forçada (considerando a pressão de profissionais que estavam havia tempos na luta pela redemocratização da sociedade brasileira e pela superação não só do tradicionalismo na profissão, mas também do conservadorismo), para a introdução, explícita do marxismo, que em tempos 
de chumbo não podia sequer ser nomeado e seus adeptos, reunidos em uma pequena vanguarda que catalisou o chumbo repressivo desse período e que manteve altiva a relevância do pensamento de Marx na e para a profissão. Esse processo não ocorreu sem problemas, e vários estudos já foram realizados a respeito da aproximação e apropriação do marxismo pelo Serviço Social. Cabe destacar o estudo realizado por Netto (1994).

O Seminário de Sumaré (1978), realizado sob o apagar das luzes da hegemonia burguesa, manifestou-se principalmente (não mais exclusivamente) por meio da tese de livre-docência de Ana Augusta de Almeida (1978), depois publicada, e apontou uma "nova proposta" para o Serviço Social. Na dialética entre continuidade e ruptura com o passado profissional, percebeu-se, nessa perspectiva, que apesar de apresentar elementos renovadores, ainda ponderava a herança profissional de cunho religioso e conservador do lastro do Serviço Social europeu. E isso num momento em que posturas conservadoras encontravam grandes dificuldades de cristalização na (auto)representação profissional, em face de dois importantes elementos que rechaçavam qualquer tentativa de resgate do tradicionalismo: a laicização profissional e a crescente ponderação de tendências católicas de cunho anticapitalista. No entanto, existiam núcleos no Serviço Social que estavam interessados num empreendimento restaurador. Tais núcleos deveriam operar com o fito de resistir às modificações trazidas pela proposta modernizadora e de aproveitar o insuperável lastro conservador, associado aos novos dilemas prático-operacionais não resolvidos por aquela perspectiva. Por outro lado, procedia também aproveitar o clima sociocultural em que dimensões psicológicas e individuais ganhavam destaque na trama das relações sociais, permitindo o resgate das tradicionais práticas face to face, além de neutralizar as vertentes que recorriam aos influxos do pensamento crítico-dialético. A nova roupagem do conservadorismo exigia e valorizava a elaboração teórica para as práticas profissionais, criticando os substratos recolhidos das Ciências Sociais. Em síntese, tratava-se da rejeição dos padrões teórico-metodológicos da tradição positivista considerados 
inadequados para apreender a existência humana. A explicação do "pensamento causal" deveria ser substituída pela compreensão, através de uma vinculação com o pensamento fenomenológico. Os valores da "Reatualização do Conservadorismo" eram os cristãos, e os objetivos constituíam um repúdio às práticas ajustadoras, dando prioridade à "transformação social”, pela via exclusiva do indivíduo (Netto, 1994).

O Seminário de Sumaré (assim como o IV Seminário de Teorização do Serviço Social realizado em Alto da Boa Vista, entre os dias 5 e 9 de novembro de 1984) teve um número representativamente menor de profissionais, em face dos seminários de Araxá e Teresópolis (CBCISS, 1980). Os conferencistas e os temas das conferências em Sumaré também possuíam uma característica diferenciada e que até então não tinham tido espaço de debate no interior da profissão, desde as primeiras manifestações do Movimento de Reconceituação. O seminário foi dividido em três direções teóricas e metodológicas: positivismo, fenomenologia e a "dialética". Houve aqui um novo direcionamento. A modernização da profissão não era mais referendada numa única vertente, sendo que a vertente modernização conservadora participou desse seminário com pouca expressão. O caminho para elucidar essa abertura teórica oferecida pelo CBCISS consistiu na movimentação e rearticulação dos assistentes sociais em face do relaxamento da opressão, característica do Estado burguês nesse período, tendo em vista a política de reforma do próprio governo militar, autocrático e burguês. O segmento resistente, questionador e de vanguarda da profissão denunciava a direção modernizadora e conservadora em suas posições e formulações. Por esse motivo, é patente a inflexão do CBCISS, inaugurando a interlocução plural, motivada pelo envolvimento da profissão no debate e no enfrentamento político, pressionando por mudanças na conjuntura brasileira, ao empurrar para a frente a busca da autonomia da democracia brasileira e de marcar posição na recusa do desalento da perspectiva modernizadora.

Creusa Capalbo (CBCISS, 1980) representou o CBCISS nas conferências sobre a fenomenologia e sobre a dialética, apesar da fragilidade 
e superficialidade das questões apresentadas na conferência: "Considerações sobre o pensamento dialético em nossos dias”, de cariz eclético e sem aprofundamento, uma vez que a dialética em Marx, Engels, bem como em Gramsci, é compreendida com a contribuição da dialética de Kierkegaard, Heidegger, Merleau-Ponty e Althusser, só para citar alguns.

Em face da abordagem simplista evocada do Seminário de Sumaré, não houve propriamente uma interlocução que pesasse no debate e atendesse a necessidade de superação e crítica do conservadorismo historicamente constituído na profissão. Os manifestantes das correntezas críticas, radicais e subterrâneas (Netto, 1994) apropriadas por aquele segmento profissional que esteve exilado, forçado a se esconder, que padeceu com a tortura por defender direitos, liberdade e democracia, insatisfeitos com os rumos e as condições do pluralismo oferecido pelo CBCISS, articulam a categoria profissional com base nos sindicatos regionais de assistentes sociais, docentes e uma vanguarda profissional para a grande virada no III Congresso Brasileiro de Assistentes Sociais (Abramides e Cabral, 2009).

\section{Referências}

ALAYÓN, N. Acerca del Movimiento de Reconceptualización. Serviço Social \& Sociedade, São Paulo, n. 84, ano XXVI, 2005.

ABRAMIDES, M. B.; CABRAL, M. S. A organização política do Serviço Social e o papel da Ceneas/Anas na Virada do Serviço Social brasileiro. In: CFESS: 30 anos do Congresso da Virada. Brasília: CFESS, 2009.

ALMEIDA, A. A. Reflexão sobre o problema da reconceituação do Serviço Social. Debates Sociais, Rio de Janeiro, n. 19, ano X, 1974. Alves, 1978.

Possibilidades e limites da teoria do Serviço Social. Rio de Janeiro: Francisco

ALVES, G. Trabalho e sindicalismo no Brasil dos anos 2000: dilemas da era neoliberal. In: ANTUNES, R. (Org.). Riqueza e miséria do trabalho no Brasil. São Paulo: Boitempo, 2006.

O novo (e precário) mundo do trabalho: reestruturação produtiva e crise do sindicalismo. São Paulo: Boitempo, 2000. 
ALVES, M. H. M. Estado e oposição no Brasil (1964-1984). Petrópolis: Vozes, 1987.

ANTUNES, R. Os sentidos do trabalho: ensaio sobre a afirmação e a negação do trabalho. 2. ed. São Paulo: Boitempo, 2000.

A era da informalização e a época da informalização: riqueza e miséria do trabalho no Brasil. In: ANTUNES, R. (Org.). Riqueza e miséria do trabalho no Brasil. São Paulo: Boitempo, 2006.

; DRUCK, G. A epidemia da terceirização. In: ANTUNES, R. (Org.). Riqueza e miséria do trabalho no Brasil III. São Paulo: Boitempo, 2014.

AQUÍN, N. Reconceptualización: um trabajo social alternativo o uma alternativa al trabajo social? Serviço Social \& Sociedade, São Paulo, n. 84, ano XXVI, 2005.

BARAN, P. A. e SWEEZY, P. M. Capitalismo monopolista. Rio de Janeiro: Zahar, 1974.

BIHR, A. As formas concretas do trabalho abstrato. In: ANTUNES, R. (Org.). Riqueza e miséria do trabalho no Brasil III. São Paulo: Boitempo, 2014.

BRAGA, R. A reestruturação do capital: um estudo sobre a crise contemporânea. São Paulo: Xamã. 1997.

BRAVERMAN, H. Trabalho e capital monopolista: a degradação do trabalho no século XX. 3. ed. Rio de Janeiro: Guanabara Koogan S. A., 1987.

CBCISS. Debates Sociais, Rio de Janeiro, n. 60, ano XXXVII, 2002.

Documento de Sumaré. Debates Sociais. Rio de Janeiro, suplemento n. 8, ago. 1980.

FERNANDES, F. Sociedade de classes e subdesenvolvimento. 5. ed. revista. São Paulo: Global, 2008.

. Capitalismo dependente e classes sociais na América Latina. 3. ed. Rio de Janeiro: Zahar Editores, 1981.

A revolução burguesa no Brasil. Rio de Janeiro, Zahar, 1975.

IAMAMOTO, M. V. O Serviço Social na contemporaneidade: trabalho e formação profissional. São Paulo: Cortez, 1998.

; CARVALHO, R. Relações sociais e Serviço Social no Brasil: esboço de uma interpretação histórico-metodológica. 6. ed. São Paulo: Cortez Editora; Lima: Celats, 1988.

JUNQUEIRA, H. I. Quase duas décadas de reconceituação do Serviço Social: uma abordagem crítica. Serviço Social \& Sociedade, São Paulo, n. 4, ano II, 1980.

HARVEY, D. A produção capitalista do espaço. 2. ed. São Paulo: Annablume Editora, 2006.

NETTO, J. P. O Serviço Social e a tradição marxista. Serviço Social \& Sociedade, São Paulo, n. 30, ano X, 1989.

. Capitalismo monopolista e Serviço Social. São Paulo: Cortez Editora, 1992.

Ditadura e Serviço Social: uma análise do Serviço Social no Brasil pós-64. São

Paulo: Cortez Editora, 1994. 
NETTO, J. P. Pequena história da ditadura brasileira (1964-1985). São Paulo: Cortez Editora, 2014.

A Reconceituação: ainda viva, 40 anos depois. In: ALAYÓN, N. (Org.) Trabajo social latino-americano: a 40 años de la Reconceptualización. Buenos Aires: Espacio Editorial, 2005a.

. O Movimento de Reconceituação: 40 anos depois. Serviço Social \& Sociedade, São Paulo, n. 84, ano XXVI, 2005b.

\section{Sobre a autora}

Isaura G. C. Aquino - Professora adjunta de Serviço Social. Doutorado e pós-doutorado pela Universidade do Estado do Rio de Janeiro.

E-mail: isauraaquino@gmail.com 